This item was submitted to Loughborough's Research Repository by the author.

Items in Figshare are protected by copyright, with all rights reserved, unless otherwise indicated.

\title{
Somatic and cultural knowledge: Drivers of a habitus-driven model of tacit knowledge acquisition
}

PLEASE CITE THE PUBLISHED VERSION

https://doi.org/10.1108/JD-03-2018-0044

PUBLISHER

Emerald

VERSION

AM (Accepted Manuscript)

\section{PUBLISHER STATEMENT}

This work is made available according to the conditions of the Creative Commons Attribution-NonCommercialNoDerivatives 4.0 International (CC BY-NC-ND 4.0) licence. Full details of this licence are available at: https://creativecommons.org/licenses/by-nc-nd/4.0/

\section{LICENCE}

CC BY-NC-ND 4.0

\section{REPOSITORY RECORD}

Chen, Hui, Jose Miguel Baptista Nunes, Gillian Ragsdell, and Xiaomi An. 2019. "Somatic and Cultural Knowledge: Drivers of a Habitus-driven Model of Tacit Knowledge Acquisition". figshare. https://hdl.handle.net/2134/36895. 


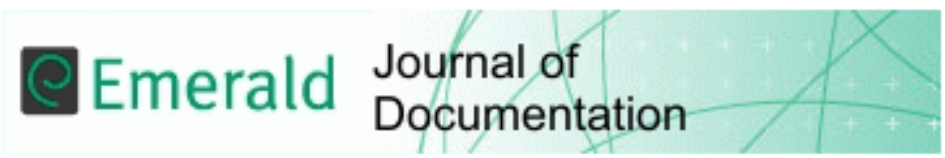

\section{Somatic and Cultural Knowledge: Drivers of a Habitus- Driven Model of Tacit Knowledge Acquisition}

\begin{tabular}{|r|l|}
\hline Journal: & Journal of Documentation \\
\hline Manuscript ID & JD-03-2018-0044.R2 \\
\hline Manuscript Type: & Article \\
\hline Keywords: & $\begin{array}{l}\text { Somatic Knowledge, Cultural Knowledge, Tacit Knowledge Acquisition, } \\
\text { Tacit Knowledge Sharing, Habitus, Chinese Software Organisations, } \\
\text { Continuous Change }\end{array}$ \\
\hline \multicolumn{2}{|l}{} \\
\hline
\end{tabular}

\section{SCHOLARONE Manuscripts}




\title{
Somatic and Cultural Knowledge: Drivers of a Habitus-Driven Model of Tacit Knowledge Acquisition
}

\begin{abstract}
:
Purpose - The aim of this study was to identify and explain the role of individual learning and development in acquiring tacit knowledge in the context of the inexorable and intense continuous change (technological and otherwise) that characterizes our society today. Furthermore, the purpose was to investigate the software $(S W)$ sector, which is at the core of contemporary continuous change and is a paradigm of effective and intrinsic knowledge sharing. This makes the SW sector unique and different from others where knowledge sharing is so hard to implement.
\end{abstract}

Design/methodology/approach - The study employed an inductive qualitative approach based on a multi case-study approach, composed of three successful SW companies in China. These companies are representative of the fabric of the sector, namely a small and mediumsized enterprise (SME), a large private company and a large state-owned enterprise (SOE). The fieldwork included forty-four participants who were interviewed using a semi-structured script. The interview data was coded and interpreted following the Straussian grounded theory pattern of open coding, axial coding, and selective coding. The process of interviewing was stopped when theoretical saturation was achieved after a careful process of theoretical sampling.

Findings - The findings of this research suggest that individual learning and development are deemed to be the fundamental feature for professional success and survival in the continuously changing environment of the $S W$ industry today. However, individual learning was described by the participants as much more than an mere individual process. It involves a collective and participatory effort within the organization and the sector as a whole, and a knowledge sharing process that transcends organizational, cultural and national borders. Individuals in particular are mostly motivated by the pressing need to face and adapt to the dynamic and changeable environments of today's digital society that is led by the sector. Software practitioners are continuously in need of learning, refreshing and accumulating tacit knowledge, partly because it is required by their companies, but also due to a sound awareness of continuous technical and technological changes that seem only to increase with the advances of information technology. This led to a clear theoretical understanding that the continuous change that faces the sector has led to individual acquisition of culture and somatic knowledge that in turn lay the foundation for not only the awareness of the need for continuous individual professional development, but also for the creation of habitus related to knowledge sharing and continuous learning.

Originality/value - The study reported in this paper shows that there is a theoretical link between the existence of conducive organizational and sector-wide somatic and cultural knowledge, and the success of knowledge sharing practices that lead to individual learning and development. Therefore, the theory proposed suggests that somatic and cultural knowledge are crucial drivers for the creation of habitus of individual tacit knowledge acquisition. The paper further proposes a Habitus-Driven Individual Development (HDID) Theoretical Model that can be of use to both academics and practitioners interested in fostering and developing processes of knowledge sharing and individual development in knowledge-intensive organisations. 
Keywords: Somatic Knowledge, Cultural Knowledge, Tacit Knowledge Acquisition, Tacit Knowledge Sharing, Habitus, Chinese Software Organisations, Continuous Change

\section{Introduction and Research Context}

As proposed by Botha et al. (2008) rapid and continuous change is a characteristic of the modern business and social environment.

"Businesses are forced to transform themselves fundamentally to survive in a challenging economy. Transformation implies change in the way business is conducted, in the way people perform their contribution to the organisation, and in the way the organisation perceives and manages its vital assets, which increasingly are built around the key assets of intellectual capital and knowledge." (Botha et al., 2008, p.xvii)

This view is compatible with a traditional knowledge management proposition that competitive advantage in this changing modern world can be built around managing, preserving and protecting knowledge assets (Gao et al., 2008). It also implies that in order to face the uncertainties and inexorable change that, nowadays, characterizes the knowledgeeconomy age, organisations and social groups should endeavour to succeed in complex organisational processes related to knowledge representation, storage, dissemination and use (Amalia and Nugroho, 2011; Jashapara, 2011). However, the characteristics of this actionable knowledge (Jashapara, 2011) are complex, dynamic and highly dependent of individual knowledge construction processes, needs and practical use (Chen, 2015). This not only makes knowledge, especially tacit knowledge, difficult to capture, represent and maintain by organisations (Nonaka et al., 2000), but rapidly outdated in a continuously changing world of practice. Continuous change is not the rare, episodic phenomenon described by punctuated equilibrium models that were valid until the early nineties and considered change to be infrequent, risky and only to happen if strictly necessary (Brown and Eisenhardt, 1997). Rather, it is endemic to contemporary organisations and characterised by short product and process life cycles, rapidly shifting competitive landscapes and the ability to engage in rapid and relentless evolution and change (Eisenhardt, 1989; D'Aveni, 1994). Being able to face and take opportunity of the challenges posed by continuous change is a crucial capability for organisational competition and survival. Static models of knowledge management are therefore ill equipped to support this relentless type of change.
"Organisations are about people. In order to manage change effectively, we need to understand how change affects people at an emotional and cognitive level. There are a number of relatively predictable phases that people encounter linked with their ability to exercise control over a new situation [incremental change; bumpy incremental change and discontinuous change]." (Jashapara, 2011, p.299)

Jashapara (2011) is essentially right in this assertion, but nowadays continuous change is almost always discontinuous change, that is transformational change that occurs at any time internally and externally, globally and faster than the ability of organisations to provide 
carefully planned responses to it. As put forward by Jashapara (2011) himself, the best response to this now prevalent type of change is the adoption of well-established models of active learning, double loop learning and reflective practice (Argyris and Schön, 1978, Carayannis, 1999). Therefore, knowledge management and organisational learning "must go beyond simple replication to application, change, refinement. It must include 'rules for learning' and their change and adaptation, rather than the rote iteration of past successful actions" (Carayannis, 1999). Knowledge is the reasoning made to use information, skills and intuitions to actively guide task execution, problem-solving, and decision making. This knowledge can then be used to perform, learn and share (Beckman, 1997). Externalisation of tacit knowledge also acquires a different meaning, that is to enable organizational learning so that reflections, interpretations, learning and knowledge are accessible to others rather than just the discoverer (Carayannis, 1999). Therefore, the focus of knowledge management and organisation learning should shift to knowledge sharing (KS), that is widely acknowledged as an effective strategy to build competitive advantages in all types of organisations (McEvily et al., 2000). To support continuous change, KS becomes the crucial aspect in individual learning and peer knowledge sharing as a process of tacit knowledge externalisation. For this research, KS is the result of all the interactive activities related with transferring or disseminating knowledge between individuals, groups, and even organisations (Chen, 2015).

This paper focuses on tacit knowledge that is acquired and obtained through professional practice and human experience in the context of the SW industry in China. This industry is considered to be "high-velocity" (Brown and Eisenhardt, 1997), thus characterised by an extraordinary high rate of change that has lasted for more than 30 years. Therefore, coping with this type of continuous change has been key to competitive success since its early years (Bourgeois and Eisenhardt, 1988). As can be observed from the age of many of the references used, continuous change is not a new issue and has been debated for decades; however there is a lack of agile, flexible and adequate theoretical propositions linking knowledge sharing, individual learning and tacit knowledge acquisition. The research in this paper aims to contribute to this debate that has been somewhat forgotten and taken for granted in the ferocious competitive world of the SW Industry.

\section{Literature Review}

\subsection{SW Industry as a Knowledge-Intensive Sector}

The SW industry has long been recognized as a knowledge-intensive industry (Dingsoyr, 2002). Knowledge-intensive companies are usually defined in contrast to labour-intensive or capital-intensive companies (Nunes et al., 2006) and were characterized by Alvesson (1995, p. 6) by the following factors:

- significant incidents of problem solving and non-standardized production;

- creativity on the part of the practitioner and the organisational environment;

- heavy reliance on individuals (and less dependence on capital) and a high degree of independence on the part of the practitioners;

- high educational levels and a high degree of professionalisation on the part of most employees;

- traditional concrete (material) assets are not a central factor but instead the critical elements are in the mind of employees and in networks, customer relationships, manuals and systems for supplying services;

- heavy dependence on the loyalty of key personnel; 
- considerable vulnerability when personnel leave the company.

From a knowledge management (KM) perspective and when applied to the SW sector this characterization leads to three different significant problems:

- there is a crucial reliance on tacit knowledge;

- there is a high risk of loss of knowledge and efficiency due to high turn-overs of staff;

- there is a high vulnerability due to fast rates of change.

\subsection{Risks of Reliance on Tacit Knowledge and High Turn-overs of Staff}

The two issues at the top of this list are usually addressed by good KM practices. KM practices aim to maximize organisational and individual knowledge by extracting tacit and implicit knowledge and translating these into explicit knowledge, which then can be interpreted, represented, codified, stored, retrieved, shared and disseminated (Nunes et al., 2006). Tacit knowledge, one of the more important focuses of KM since Nonaka (1994) (explained in Nonaka et al. (2000)) proposed his now well established SECI model, and is usually defined as information residing in the minds of individuals (Alavi and Leidner, 2001) as a result of an individual's experiences and understanding (Marwick, 2001). Tacit knowledge is therefore hidden or non-verbalised; intuitive and unarticulated knowledge (Cavusgil et al., 2003) that is embedded in individual's mind and includes: insights, hunches, intuitions, and skills that are highly personal and difficult to formalize, and as a result are hard to communicate or share with others (Nunes et al., 2006).

"Knowledge has the active and subjective nature represented by such terms as 'commitment' and 'belief' that is deeply rooted in individuals' value systems. Information becomes knowledge when it is interpreted by individuals and given a context and anchored in the beliefs and commitments of individuals. Hence, knowledge is relational: such things as 'truth', 'goodness' and 'beauty' are in the eye of the beholder. As Alfred North Whitehead stated, "there are no whole truths; all truths are half-truths" A. N. Whitehead as recorded by Price (1954).

This internal and constructionist nature of tacit knowledge makes its management very difficult; it cannot be managed in ways similar to more tangible organizational assets, including explicit knowledge (equated by Wilson (2002) to information). However, in SW knowledge intensive companies, with high rates of staff turnover and rapid rates of change and evolution this is exactly the type of knowledge that is crucial for competition, innovation and survival, as shown in Figure 1. 
Most innovation, new designs and close compliance with user requirements comes from a good mutual understanding, trust and shared experiences, which are the product of constructionist social negotiation and individual internal knowledge creation over long periods of time. This acquired tacit knowledge is mostly stored in designs, applications and the minds of those analysts and programmers that participated in the development process. During this constructionist social negotiation process and shared experiences with customers and markets, technical participants acquire skills and knowledge far beyond their traditional computer science background such as communication, articulation of technical options and opportunities, negotiation and persuasion. This line of reasoning and knowledge acquisition process follows a practice-based epistemology school of thought, which was very competently discussed by Cook and Brown (1999) in opposition with more traditional objectivist epistemologies. This practice-based approach proposes that knowledge is created, shared, and learnt through interactions with the social and physical world rather than direct knowledge transfer. Therefore, externalizing, collecting, storing, sharing and disseminating this very important tacit knowledge is the crucial aspect in $\mathrm{KM}$ for intensive knowledge companies, such as SW companies.

Cook and Brown (1999) define practice as "the coordinated activities of individuals and groups in doing their 'real work' as it is informed by a particular organizational or group context". This is directly related to assertions by Vickers (1976) that pre-date KM discussions and, as quoted by Cook and Brown (1999), clearly proposed that every human activity group has not only its own set body of knowledge, but its own ways of doing things, creating understandings and knowing. For the purpose of this research, we are interested in how this process of knowing in the SW sector results in tacit knowledge that can be later be externalized, articulated and stored. According to Dewey (1922), one of the most influential American pragmatist philosophers of recent time, knowing is something we do, not something that we possess. This understanding was further clarified by Cook and Brown (1999) associating "knowing" with the epistemological dimension of action itself as follows:

"By "knowing" we do not mean something that is used in action or something necessary to action, but rather something that is a part of action (both individual and group action). "Knowing" refers to the epistemic work that is done as part of action or practice, like that done in the actual riding of a bicycle or the actual making of a medical 
diagnosis. Knowing is dynamic, concrete, and relational." (Cook and Brown, 1999)

This understanding poses severe challenges to the SW sector, which is not only a knowledge intensive sector but is also highly specialized and specific in work practices. These work practices will not only differ and diverge between organizations, but will very often vary according to the sectors and customers being served. The loss of experienced and knowledgeable employees may result in long periods of reduced efficiency until levels of tacit knowledge in replacement staff are at a similar level to those who leave. Processes of social negotiation, trust building and internal knowledge construction are lengthy and difficult. This problem is compounded as the usual human resource strategies of internal rotation and replacing individuals with similar qualified and hierarchical equivalent others may result in disaster due to the embeddedness of the processes of knowing, action and group behavior. This makes internal moves inside the organization extremely risky and may result in catastrophic lacks of efficiency.

Therefore, there is the need not only to externalize and articulate tacit knowledge, but also to fully understand how this knowledge was acquired and what work practices and knowledge sharing processes led to the different aspects of knowing: the main raison d' être of this paper.

\subsection{Vulnerability to Fast Rates of Change}

The SW industry is usually related to SW engineering. However, this simplification is reductionist, misleading and damaging to the sector and has led to decades of confusion and difficulties when work practices, practitioners in the field and project aims do not fall into the traditional technical image of a 'programming' (Chen et al., 2012). In fact, the SW sector includes much more than just the technical design, development, implementation and maintenance of software. It also includes a number of not so technical activities such as:

- negotiation of meanings, requirements, features and compromises:

- project and change management;

- training and documentation;

- user and customer support, advise and consulting.

The need for the creation, acquisition and adoption of knowledge that is practice-based and practice specific creates challenges that go far beyond the technical ones. However, due the dominance of the traditional engineering and technical view of the sector, there is very little in the literature on what aspects of professional and personal experience in the mind of the employees need to be codified in order to maintain the sustainability and success of SW organizations. This is of particular concern in an industry sectors with high staff turnover and low company survival rates (Chen et al., 2012). From the argumentation above, it is also to be expected that successful KM implementation can improve the development of software effort and process. In particular well implemented and efficient KS practices can support SW companies in facing changeable business environments, transitions to new and constantly emergent technologies, and very high personnel turnovers that characterize the sector (Dingsoyr, 2002; Mishra and Bhaskar, 2011). It is exactly this constant changing environment that poses severe challenges to the companies in the sector. 
This is not a new phenomenon and it could be argued that is has been a constant in the sector since its inception as noted by Michael Dell (1993) the founder of Dell Computer Corporation:

"The only constant thing about our business [the SW industry] is that everything is changing. We have to take advantage of change and not let it take advantage of us. We have to be ahead of the game" Michael Dell (1993) founder of Dell Computer Corporation as quoted by Narayandas and Kasturi (1995).

This awareness of a sector in constant evolution and change is particularly complex in the SW sector as change is occurring inside and around the sector. Since its main focus is clearly information technology, the first driving force for change in the sector is exactly the rapid and constant change of technology, technological solutions, programming languages, operating systems and development environments. It is not surprising that such an awareness is being labelled both as a risk and as an opportunity within the sector. For instance, Marc Benioff, founder, chairman and CEO of salesforce.com and a veteran of Apple and Oracle where, at age 23, he became that company's youngest vice president, is quoted by Israel (2013) as follows:

\begin{abstract}
"The only constant in the technology industry is change. We are now in the most exciting time of our industry. The world is being re-shaped by the convergence of social, mobile, cloud, big data, community and other powerful forces. The combination of these technologies unlocks an incredible opportunity to connect everything together in a new way and is dramatically transforming the way we live and work." Benioff quoted by Israel (2013).
\end{abstract}

This statement clearly recognizes the other aspect that affects the SW sector as much as technological change: a business environment with constant, dramatic and, at times, revolutionary change. To thrive in this turbulent environment, SW companies must sustain continuous organizational innovation though the forging of creative workforce cultures (Highsmith and Cockburn, 2001). These changes result in evolving customer expectations, demands on new technology, changing regulations and rapidly developing cultural trends, and are pushing SW to regularly rethink and adapt their business models, processes and organizational structures to new conditions in order to stay competitive (Sofware AG, 2015).

This dual nature of the continuous change that is becoming the norm in the SW industry is now increasingly triggering the necessity for greater understanding of the role of tacit knowledge and its dissemination both internal and external to the organization (Venkitachalam and Busch, 2012). However, knowing and tacit knowledge are as a discussed above closely related to experience and practice. If these practices and experiences are rapidly changing then acquisition of tacit knowledge will be harder; time for reflection and articulation will be even shorter and the usefulness associated with elaborate processes of externalization, embodiment and dissemination will become questionable at best. This is the realization behind the research project reported in this paper that led the authors to explore how tacit knowledge is currently being created by practitioners in the SW industry when faced with such rapid and constant change. In particular, how action is embodying and resulting in knowing. 


\section{Research Design}

\subsection{Research Question}

The research project reported in this paper is driven by the general aim of exploring and establishing how individuals in the SW industry learn and acquire tacit knowledge as a result of their work practices and in the face of continuous and not-necessarily incremental and linear change. Since the majority of the authors are resident academics in China and, in order to explore this aim in depth, a multi-case approach in the Chinese companies sector was adopted. This multi-case study was influenced and shaped by following the research questions:

- How are practitioners learning and acquiring tacit knowledge in the context of their world of practice in the software industry?

- What practical strategies, tools and mechanisms do these practitioners use?

\subsection{Research Design and Approach}

A multi case-study approach combined with a grounded theory (GT) inductive qualitative research approach for data collection was selected to respond to the above research questions.

The fieldwork was conducted in the SW sector in China using three types companies of companies that are representative of the fabric of the sector, namely a small and mediumsized enterprise (SME), a large private company and a large state-owned enterprise (SOE). One of the case-studies, an SME company called BAIDUCHUAN Information Technology Co., Ltd., is a multimedia software research and development company, founded in September 2010 in Xiamen City (Fujian Province, South of China). The second company, is a private company called UNIS Archives (Bosi at the time of the research), which mainly designs and develops electronic archives systems as well as providing the professional consulting for digitalisation of archives. The third one is a state-owned company called Yirong Info Co., Ltd., founded in 2002. It is an innovative enterprise fully owned and controlled by Great Power Science and Technology Co., Ltd (GPST) which provides IT support services, and builds and maintains the information systems for the national State Grid of China.

This multi case-study strategy was not selected aiming at producing a comparative study or to enable comparison and contrast of practices and understandings across the three different types of companies. GT would not be an appropriate methodology for comparative studies and just one of each company would not allow for a generalizable comparative study. Quite in the contrary, this multi case-study strategy approach was selected as a theoretical sampling strategy required in GT and defined as "the process of data collection for generating theory whereby the analyst jointly collects, codes, and analyzes his data and decides what data to collect next and where to find them, in order to develop his theory as it emerges." (Glaser \& Strauss 1967, p.45)

Based on this definition, sampling is an ongoing process. This represents an important difference between GT and more traditional approaches to inductive research and interviewing. GT proposes that data collection and analysis are not separate and dissociated processes. That is, it is not expected that the researcher will collect all the data in one process and subsequently analyse all the collected data. Data is collected and analysed and the results of this analysis may direct the data collection process into different directions, e.g. different 
contexts, different people or even include different questions. Furthermore, this means that, contrary to other approaches, the interview script and respective questions may also evolve according to theoretical sampling, that is, it is not a data collection tool created at the start of the project and then used uniformly throughout the collection process. Moreover, the sample can guide the collection of data. The sample is also selected and "redefined by the emerging theory" aiming at theoretical saturation, and therefore it is "impossible to predict the size of the sample prior to starting the study" (Rodon \& Pastor 2007, p.73). Accordingly, the choice for the multi-case strategy followed this principle of theoretical sampling and the use of the three different contexts is therefore purposive, evolutionary and informed by the data analysis. In this sense, no significant weightings were given to the relative proportion of each casestudy, the data collection and analysis progressed from one case-study to another until theoretical saturation was achieved.

The data collection process started with the SME, followed by the large private company and finally the SOE. Because of its small size the SME could only offer a small amount of interviewees (6). The private company on the other hand offered a larger number of interviewees and allow the study to come closer to theoretical saturation (25). The SOE was used a last implementation of theoretical sampling and, because theoretical saturation was achieved early (no new codes emerged in three consecutive interviews), only contributed with a smaller number of interviewees (13).

It was expected that by using three very different organizational environments the data collection could produce a richer, better explained and better understood theory for the SW sector in China, as well as speed up analysis and theoretical saturation.

\subsection{Data Collection and Analysis}

This study used a Straussian GT approach as proposed by Strauss and Corbin (1998). This approach was deemed to be particularly appropriate for this research as there is a lack of literature in addressing the specific area around the research questions. Straussian GT uses an interpretivist epistemological stance and advocates that inductive theory can be generated from qualitative data collected within particular social contexts and obtained directly from participants in the phenomenon being studied, without the bias of preconceived theoretical frameworks (Chen et al., 2016). GT has previously been used in KM studies as well as in IS/IT research, and is therefore well-suited for studies such as the one reported in this paper.

The study used semi-structured interviews as the main method of data collection. The interviews used an evolving interview script rather than a positivist interview protocol as discussed in section 3.1. This means that the interview questions were added as the understanding of phenomenon grew in the research team and according to the needs for further theoretical sampling. Interview questions themselves were open-ended in order to enable the researcher to focus on the more significant issues and to elicit substantial perspectives, opinions and ideas from the interviewees. The interview script was designed in order to enable participants to discuss issues of tacit knowledge in the context of their practice and in relation to the typical aspects of SW development. The semi-structure aspect of the script design consisted in defining general areas of this SW development (Planning and Project Management, Requirement Specification, Design, Prototyping, User Feedback Capture, etc.). These areas were deliberately made generic as different companies use very different methodologies or selected components of methodologies (e.g. UML was used in the three companies, but with completely different interpretations, use of diagrams and project 
management stages). For each of the general areas a set of questions was prepared to be used as prompts and follow-up queries, but not necessarily to be used sequentially or extensively. Furthermore, a work area was left at the end of each set of questions, so that the interviewer could take notes, memos or even write down extra-questions that emerged from the discussion with the interviewee. Figure 2 illustrates the script structure.

\section{b) Capturing Requirements Phase}

\section{客户需求调研.}

\footnotetext{
What kind of experience and knowledge do you think could help you to specify and express customers' needs, and definite in terms of system's interface?

您认为什么样经验和知识能够帮助您捕捉和表述客户的需求, 并转化为专业技术语言记录下 来? 。

What kind of knowledge do you think it could help you to understand and analysis the customers' requirements?

您认为什么样经验和知识能够帮助您理解和分析客户的需求?

What kind of knowledge do you think it could help you to present the customers' needs in term of both business and technical level? .

您认为什么样经验和知识能够帮助您从业务和技术应用的层面表达出客户的需要?

When you work with others, do you think there are any skills involved which can challenge or affect the efficiency of your working? (good communication channels, efficient work division and good leadership)

当您与他人共事时, 您认为什么样的技能可能会影响或帮助您的工作效能?（好的沟通渠道, 有效的工作分工，好的领导才能）.

What type of knowledge from the projects you are on now would you like to transfer to new projects?

您现在这个项目中所运用的什么样知识，会积累运用下一个项目中？

What type of knowledge has been suitable for reuse from the projects you have been working on earlier?

您现在这个项目中运用的那些知识，是来自于上一个项目的积累？
}

Figure 2. Illustration of the semi-structured interview script used in this research.

The process of interviewing was only stopped when theoretical saturation was achieved. Since the epistemological stance adopted by the study is an interpretivist one, there is no expectation that a full constructivist process of social negotiation of meanings occurred during the short period of interview (in average 1 hour). The interviews collected evidence, opinions and stories that were then interpreted, coded and integrated in to a final theory (in our case two) at the end of the process.

The interviews were conducted in Mandarin Chinese, but all questions were originally developed in English and then translated into Chinese. Writing the questions in English enabled discussion of structure and design among the predominantly English speaking research team. 
Prior to the interview, each interviewee received introductory information about the purpose of the study and information on research ethics issues such as confidentiality and anonymity. Overall, there were 44 participants. The sampling was devised so that informants from all areas of the SW development in the company were represented, namely: 1 share holder, 5 managers, 11 project managers, $25 \mathrm{SW}$ developers, 1 human resource and 1 salesman.

All interviews were digitally recorded prior to being transcribed and codified. The data analysis followed a Straussian pattern of coding, which consists of open coding, axial coding, and selective coding.

\section{Research Findings}

The theoretical and explanatory narrative presented in this section is the product of the Straussian GT process adopted. All interviews responses were taken into account in full. The process was started with open coding of an initial set of interviews and the extraction of all codes pertaining to the phenomena being studied, followed by an initial process of axial coding that defined early categories and subcategories that encapsulate these codes. This process was then continued elliptically until theoretical saturation was achieved. Every emergent and relevant code was checked against categories and already accepted codes using the process of constant comparison.

The explanatory narrative presented in this section was then produced by choosing the best quotations for each code. During this process, the researchers tried to avoid theoretical bias, by not imposing prejudices and theoretical stances on the interviewee's statements, and accepted their views, understandings and opinions. The narrative reflects this grounded nature of category structure and codes. The linking of this emergent theory with existing theoretical propositions is done in the next section and relates the findings with established theories (e.g. Bordieu's and Alvesson's propositions).

When asked how they coped in a fast changing environment, the need for constant update of their technical and environmental knowledge and the necessity to compete with colleagues both internally in the company and externally in competitors, participants revealed different states of mind ranging from desperation to excitement. Most felt they were doing as well as their peers, all gave examples of colleagues who gave up and moved to more stable sectors, and some mentioned the ambition to move to better companies such as Huawei, Tencent or Lenovo.

In terms of how they engaged with continuous and unpredictable learning and development, all seemed to agree that there are two main modes used in the sector: individual learning and peer supported learning (learning with/from others). Despite having gone to great lengths to explain and describe individual learning, it became apparent that peer knowledge sharing was the preferred and most commonly used process for rapid learning, just-in-time problem solving and rich discussion. The nature of this peer knowledge sharing was described as being rather open and frank both internally in their organizations and externally with the wider sector, including direct competitors.

\subsection{Individual Learning}

Individual learning was defined by participants as self-driven learning activities that are undertaken by individuals without directly interacting with others. These reflect a more 
private, introspective and independent learning process, and are strongly dependent on individual's experience, motivation and ability. As shown in Figure 3, the findings for this sub-category qualified individual learning according to different modes of learning: Continuous Learning; Self-Learning; Learning by Doing; Self-Selective Learning based on Current Work; Just-in-time Learning; and Learning from External Case-Studies.

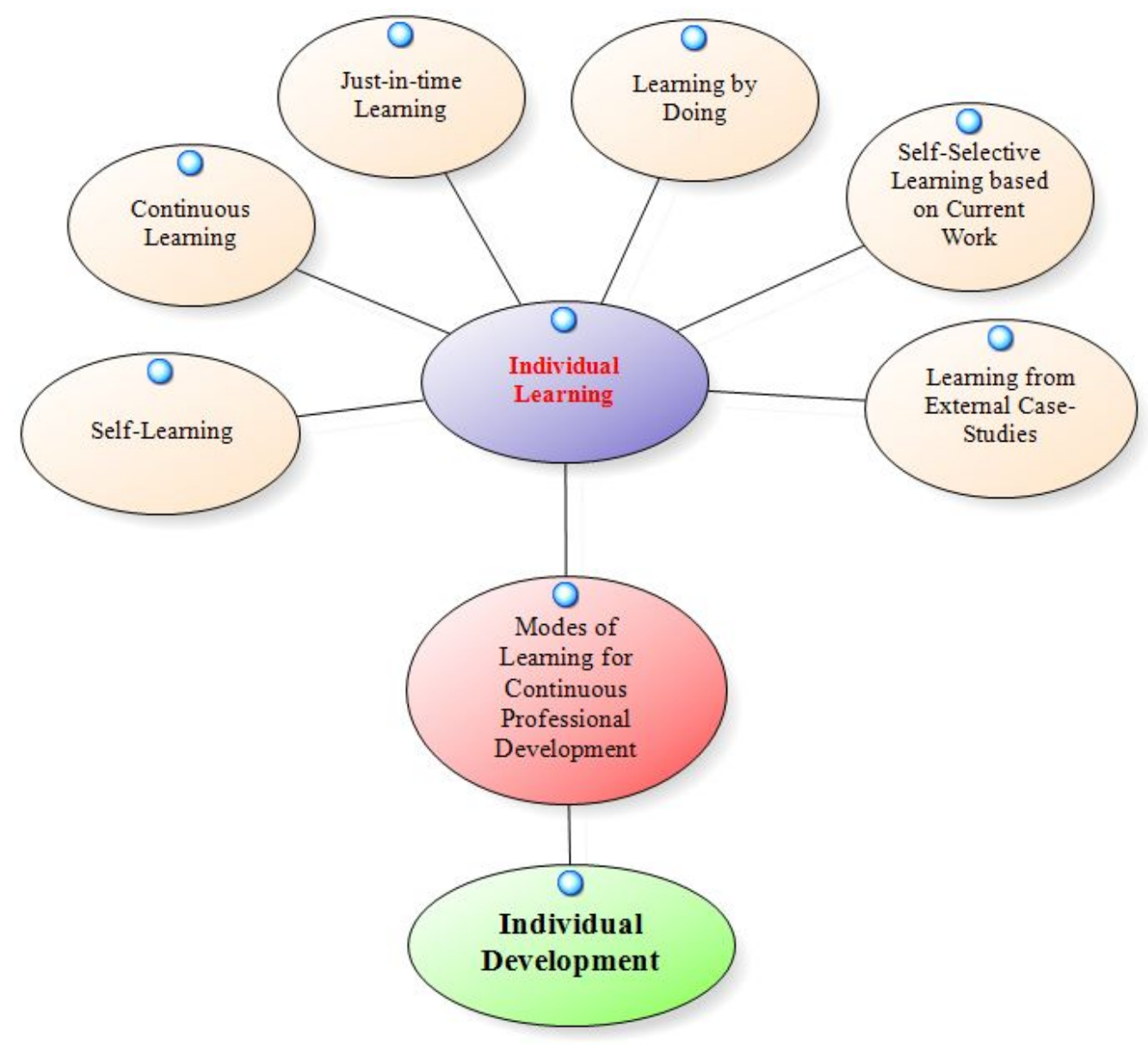

Figure 3. Individual Learning Modes in the SW Sector

Continuous Professional Development requires that individuals engage in reflective practice and continuous learning. This is necessary to define and understand development needs and was seen by interviewees as the core activity for individuals to "upgrade their knowledge and improve their abilities" (I30.12.4.D). The need for this continuous individual learning was very clearly explained by one of the developers as well as a manager:

"The job I am doing is all related to technology, which does not mean I don't need to learn more after I acquired good knowledge about one of these technologies. The IT world has been producing new stuff all the time, so working with IT requires that I keep learning ... (laughs in self-pity)." (I16.4.26.D)

"If you are able to keep your understanding of the technology up to date, then you will be also able to learn the best practices for using the latest technology." (I25.19.35.M) 
The awareness and ability of continuous learning was also used by one of the managers in relation to improving efficiency and innovative ways of work and, as such, these are a firm requirement for personal development of the employees:

"For example, for one particular SW module you may need to write ten lines of code, but I would be able to finish the same module in a single line of code ... and mine would run faster than yours. This means that I have learnt more [in terms of programming and algorithms] and that I have more experience. There is no better way [to catch up with experienced staff] ... just keep learning continuously and improving that way." (I25.19.30.M)

Therefore, "Doing software [development] requires a strong self-learning ability" (I6.2.41.D). This ability for self-learning associated with continuous learning was one of the most referred activities identified by interviewees, managers and developers alike. Self-learning was associated with each stage of SW development, such as planning, designing, programming, and testing. Examples were given by managers, project managers and developers as illustrated below.

"In terms of the new technology [proposed in the plan] ... I need to study it myself and understand the latest development of technical trends required by our project." (I4.4.19.M)

"I need to constantly understand new technology that might be useful. For example, for big data, we need study in order to choose between a relational database or NoSQL." (I26.9.23.PM)

"Electronic records systems have higher requirements in terms of system pressure and system performance. Therefore, technical requirements will be relatively higher for each development staff member. SW development is like construction of buildings which needs everyone to have the capability of working with old and newest technology, not just one special person. So the whole team needs to enhance their technological awareness and understanding." (I26.5.42.PM)

"This knowledge of using testing tools can only be learned by yourself in your own extra time. If you do not have this knowledge, you can always go online to gather the relevant information." (I13.7.17.D)

It is important to mention that web search engines and specialist web resources were mentioned as being widely used to obtain specialized information by self-learners. These learning resources are discussed in depth in 5.5.3.

An important aspect in both continuous and self-learning is the capacity to do so by reflecting on your own work and work practices and therefore learning from both successes and failures. Learning-by-doing is, therefore, one the most crucial modes of individual learning to enable the acquisition of experience and new knowledge from working practice. This was noted by several of the developers by proposing that "repetitive use of programming techniques and technology will slowly allow us to accumulate more and more experience through practice" 
(I6.2.15.D). This acquired experience may itself help in the learning process by enabling practitioners to reflect on specific aspects of their practice:

"However, now I can selectively absorb knowledge from real working practice. Moreover, if one component of knowledge is frequently used, my understanding and my retention of it would be more in-depth." (II7.2.43.D)

This view was also highlighted by a project manager who gave similar opinions:

"Well, I think experience can certainly enhance the individual's work efficiency. But experience means you have written lots [of programs and routines] before. ... Yes ... if you are asked to program modules that you were never in touch with, then you definitely cannot be fast. If you write the same type of code every day then you certainly will be faster. Moreover, you are usually able to explore ways to maximise the efficiency and fast running of your code." (I1 1.12.24.PM)

This learning-by-doing aspect of the professional practice in SW development may even imply developing skills and experience in areas that the developers had not had previous knowledge in, such as developing a sense of aesthetics which is especially useful at the stage of designing the SW, as explained by a product designer:

"I think designing SW has a relation with personal experience ... that is if you have developed a number of systems before, you would have a sense of what works. Maybe these senses are not always explicit or tangible. Sometimes it is just a kind of feeling of beauty, on how to make an interface more beautiful or on how to make the operation of the SW more convenient. This sense is usually connected with the experience of the person ... the result of intensive and frequent design of human-computer interaction." (I12.8.1.D)

Learning-by-doing was perceived to be also useful in the acquisition of leadership knowledge, as stated by one of the department managers from Bosi that expressed the view that the best way to learn how to be a leader was by reflecting on his daily practice:

"I really think that the experience of leading can only be gained from prior experience of actually leading. I think in this field of $S W$ engineering, there is always new knowledge or new ideas emerging that we need to use in our work. These new things may require different ways of managing, scheduling, monitoring and even leading ... you know ... I always need to analyse these latest things using my previous experience, extracting ways of dealing with it and applying them into my work. This ability is very important. In this way, while doing my job, my skills will continually grow and my knowledge is refined and accumulated." (I25.4.42.M)

Another important aspect raised by informants was the ability to engage with just-in-time learning, i.e. to learn if and when the developer's tasks require the learning of new techniques, algorithms, technologies or even new organisational environments and business sectors. This 
was stressed as highly desirable by a manager, especially when preparing for meetings with new customers:

"You should be ready to learn at any time. Sometimes, we need to write a report [to customers] on the second day. But I know nothing [about some of the technologies required or business environment of the customer]. So I need to search information overnight, and try to understand it, until I become a little bit more knowledgeable than the customers." (I4.4.20.M)

The need for just-in-time learning seems to be also associated with adapting to different performance requirements from different customers

"As we all know, electronic records projects require high technology in order to deal with large amounts of data, probably more than 10 million $G$ in the case I am working with, as there are higher performance requirements from the database technology. Moreover, if various business systems export data into the electronic records system, the pressure on the system will be very high. So, there is a need for higher technology, that I need to learn about." (I26.5.37.PM)

Therefore, just-in-time learning was not surprisingly mentioned by many of developers, but significantly it seems to be part of all activities related with development as expressed by content manager:

"For example, if I want to remove an element of a specific picture, or add some flash for the title or add a company watermark ... I need to learn by myself how to do it." (I3.8.1.CM)

One mode of individual learning that virtually all developers mentioned as being crucially important refers to learning from external examples, especially failures and successes in external case-studies. These are wide spread in the Internet and heavily used by the SW community worldwide, as discussed in section 5.5.3. The use of these external case-studies is highly dependent on experience and individual awareness of where to search for useful information. One developer gave an example of individual learning about big data as follows:

"We are now doing a number of studies on the architecture and technical architecture for a big data system. How do we face such a large amount of data, and how do we deal with such high concurrency? Meanwhile, we also combine [our current situation with] some experience from the Internet, such as Taobao or others who have experienced on dealing with big data." (I12.2.23.D)

Taobao, is the Chinese equivalent to ebay and the biggest consumer-to-consumer ecommerce platform in China. It contains nearly 16 million independent vendors, listing their products and shipping directly to buyers. It has applied big data analytics as the basis for their meteoric success and a common case-study for others to learn from.

Another developer gave an example of information security as follows: 
"For example, we would like to know how some of the large domestic and well-known enterprises, such as banks, have designed their security and what the technological principles behind their solutions are. That is the type of information we need to learn about and apply in our own systems. This is important because we just started to use some of these new technologies and the best way is to learn from other's success cases." (I13.5.39.D)

Many of the types of individual learning identified here can be overlapping to a certain extent, but they are clearly distinct. The need for continuous learning in a sector in permanent and inexorable evolution is certainly the most dominant concern and mode of learning according to the responses of the interviewees. However, a person might learn only when the need to learn occurs ('just in time') and therefore not in a continuous mode. Another person, may learn by looking on Weibo or on internet forums sporadically and only when by curiosity they find a new issue that attracts their attention. Others prefer "learning by doing" through trial and failure until they achieve a solution. Learning by doing requires engaging in reflexive practice that is not strictly necessary in continuous learning that may not include this type of experiential learning. Learning by doing may occur due to current work needs, due to a perceived need for learning to remain competitive or even out of curiosity in relation to emergent technologies, programming languages or software development kits (SDK). Furthermore, "self-selective learning based on current work needs" may not be a form of "just in time" and can engaged through self-planned learning strategies that may include: learning by doing, learning from others, learning form external case-studies or even traditional face-to-face training.

All these individual learning categories emerged through the process of coding and interpreting interviewee's statements and opinions. Merging and elimination of categories was done through the process of axial coding. During this process and that of selective coding the researchers tried minimize the number of categories without reducing, simplifying or deleting interviewee's contributions. Many of these terms have already clear theoretical meaning in the andragogy literature (e.g. learning by doing, experiential learning, life-long learning, just-in-time learning, etc) so when assigning names for the categories the researchers tried to avoid theoretical bias, by not always imposing well known theoretical concepts on the interviewees statements. So some of the categories (e.g. "self-selective learning based on current work") were added when existing theoretical concepts were deemed to be reductionist or not representative of interviewee's views, understandings and opinions.

This discussion has focused on individual learning triggered by self-motivation and work needs. However, continuous professional development is often more deliberately and strategically planned, so that active involvement of others helps the practitioners develop faster and become more focused. The next section addresses this learning from other aspects: through mentoring, tutoring or even formal training.

\subsection{Learning from Others}

Learning from Others refers to peer supported learning modes, i.e. learning in semi-formal settings and with active involvement of peers, mentors or external experts. This may still involve one-to-one processes and even traditional training processes in groups or classes. 
Interviewees referred to this mode of learning frequently as part of their preparation to enter the work world and more significantly to this research as part of their professional development. Learning from others was categorised according to very different aspects, as shown in Figure 4: Learning from Online Training Systems, Learning from Company Tutoring Schemes, Learning from Team Members, Learning from Internal Training Initiatives, Learning by Training Others as Instructors, Learning from Invited Experts, Learning from External Case-Studies and Learning from External Professional Training.

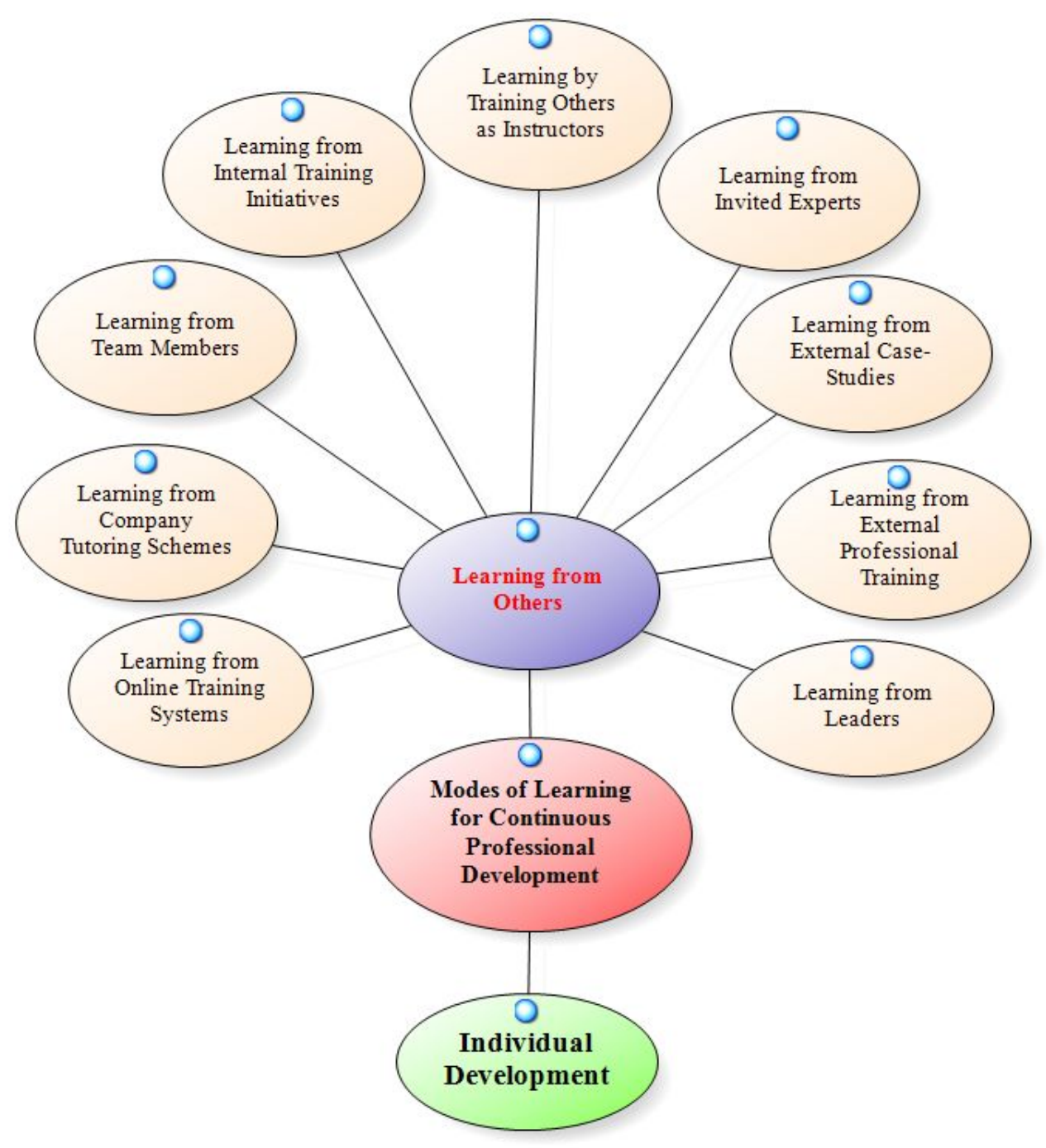

Figure 4. Peer Supported Learning Modes in the SW Sector

Learning from Online Training Systems was considered as the most convenient mode of learning by developers. It seems to suit their natural working habits as well as providing flexibility to learn at their own pace, at any time that suits them and from anywhere they can $\log$ on from. Companies and management seem to support this mode of learning as well, as they do not have to spend funds on external training and do not have to lose developers' work during the periods of training. Therefore some of the companies have made sustained efforts to develop online training materials and systems. Yirong (the large state-owned company) created what they name the "Online University" that is now heavily used: 
"Well, the training from the Online University is required and encouraged [by our boss]. He encourages and makes us to study on one or more courses every season (3 months, there are 4 seasons a year), every year. There is also an appraisal system for each year to evaluate how many hours we have spent and studied on the course though the Online University." (I9.5.24.D)

"There is a record of your account that contains the history of your study. The online training course cannot be skipped to the end if you started]. You have to watch it from the beginning to the end. Finally, there is a test after you complete the watching." (I9.5.29.D)

Yirong developers also stated that there is a wide choice of subjects and that not all of these are technical.

"The online training system has an URL for it ... you can use your account [the company's internal account] to log in and search for the subjects you like to learn ... even philosophy or management science. Some online courses are particularly designed for problem-solving. This searching is a bit like using Baidu, except the resources are all integrated." (I9.5.11.D)

The contents and materials for these courses were "bought from professional training institutions" (I9.5.20.D), according to what the company deemed necessary for their employees' individual development.

Beyond online training, interviewees also mentioned learning from company tutoring schemes, where junior practitioners are tutored or mentored by senior colleagues, coaches or “shifus [师傅]” (I20.15.38.D) assigned by company. Informants seem to be unanimous in thinking that this is the best and more effective way to gain knowledge:

"[...] Anyway, I feel I should [take the chance to] listen more and learn more during the coaching time. I might have not gone through some situations yet, but by observing [my coach's activities] and listening [to my coach's advice], I could learn how to best solve problems and even communicate with colleagues." (I33.5.9.D)

Informants also mentioned informal learning that occurs while working with peers and other team members. Junior staff seem to value this type of learning the most and mentioned how easy it is to learn and be influenced by other team members' working style and methods. Therefore, learning from team members was identified as an important way to develop knowledge and accumulate experience from others. For instance, one developer gave a very good example about learning about testing from other team members as follows:

"Another way to gain knowledge of testing tools is during the project. For example, at the very beginning, I was not familiar with the testing tools. But there was another team member really good at these. So when we worked together, I could follow his steps and learn from his experience." (I13.7.18.D) 
Interviewees also referred to more traditional internal training initiatives such as seminars and courses provided by senior or experienced staff.

"The company does encourage us to learn. Sometimes there is a training course in the company, which is taught by some of those senior and more experienced staff. This training is very specialised on the aspects of business operation and technology application that we use daily ... it is especially useful for the new employees." (I17.4.13.D)

This type of internal training seems to also provide learning opportunities for the trainers themselves. Interviewees that took roles in training others as instructors noted that the preparation of training sessions "require you have a deep understanding of the system. If you are not very familiar with it, you cannot train new staff." (I26.8.37.PM).

"If I do not train other people, I may simply look through the training document, and probably only know a certain level of each of chapter that relates to you. But if I have to give training, I should have a deeper understanding and more thorough understanding, because I need to teach everything and also use a more simple way to express all the meanings. [short period of self-reflection] ... Right ... using a simple way to express and present things during training could make people acquire a better understanding of the system. On the other hand, I can also practice and enhance my ability of expression during the employees' training." (I19.4.32.M)

If there is a training need that cannot be directly resolved using internal knowledge, informants from all three companies referred to the use of "Invited Experts". This seems to be common practice when adopting new technologies or engaging with previously unknown types of business.

"Yes, the invited experts would explain to us how to operate the new technology. I can give an example which is not about the system performance. It was about Oracle. Our developers were not familiar with DBA within Oracle, so our boss decided to invite a senior engineer from Oracle to give us training. During that training, we 
were able to communicate with him, and learn much more from this information exchange and idea interaction." (I13.7.28.D)

Invited experts may also be asked to present, describe and analyse external case-studies. This learning from external case-studies occurs through close links with other companies in order to share and learn from others' experiences, strategies and approaches to problem solution. This seems to be easier to enact by larger and state-owned companies, such as Yirong, which has an established network of influence as well as the reputation and influence to invite other experienced companies to teach their own employees, as stated by one developer from this company:

"Sometimes they [the experienced external company] will come to our company to communicate with us. Yes, they would exchange experiences [with us], and see how to help us. But in terms of the details, such as solution report, they certainly would not say too much, but our boss could help us to ask for it... Anyway, the exchange of ideas would still be helpful when we have problems." (I13.6.32.D)

According to statements of managers and perceptions of employees, if everything else fails, individuals and companies will then resort to external traditional training solutions. This external professional training was identified as important to acquire new knowledge and "keep up with knowledge the work requires" (I17.1.34.D). Moreover, the professional training institutions do not only train, but allow contact with a different learning culture that actually motivates the leaners, as remarked by one developer:

"Yes, the atmosphere in the professional training institution is completely different. [...] because the learners who went to the training institutions were spending extra money to learn IT knowledge [...] So under the great pressure, they study harder and more carefully. ... Right ... The atmosphere in the training institutions is the pressure of survival." (I36.2.4.D)

Conversely, other developers were not necessarily happy with this generic external training and claimed that the knowledge taught by this mode of learning was too broad, too difficult to assimilate in a short period of training and difficult to transfer into their realities of practice. One of those developers illustrated this as follows:

"[In the training school], you were covering too many things in one day, and sometimes you might think you have acquired some knowledge, but actually you cannot apply it or even remember how to apply it after. There is too much knowledge to learn in such an intensive time ... In fact, after completing the training, most classmates would select their own directions independently. " (I17.2.38.D)

Finally, participants also stated that they were sometimes able to learn from their leaders, as a way to gain leadership knowledge. Since as a team member, participants would have been supervised by different leaders, they could use these experiences to reflect on strategies that were successful and others there were less so. One project manager gave an example as follows: 
"Personally, I think, I probably learnt more from the leader of my previous project in my old company. Yes ... in my previous company, there was a team leader in charge of project management and I learnt very much from him in relation to his ways of leading and methods of monitoring the project." (I1.5.11.PM)

Leaders themselves stated that they sometimes sought advice and learned from other leaders and in doing so gained from their experience and strategies. One of the installation project managers from Bosi gave the following example:

"For example, as I just mentioned, my team member [name deleted here] was difficult to manage, and sometimes he did not even listen to me. I had to ask other colleagues on how to deal with this type of issue. A senior manager [name deleted here] gave me a lot of support and advice. He gave me examples on how he dealt with similar situations and what he would do in my place. I have learnt a lot from him." (I23.5.22.PM)

"[referring to another manager and a different problem] Yes, I adopted his advice. I understood that there is no need to monitor my team members every day, every minute. I just needed to schedule the tasks for them, and ask about progress at regular times. But not as frequently as I was doing before. I understood that they felt stressed and even offended if I was asking and monitoring them so often. This advice was effective, and I am still doing things in this way." (I23.5.28.PM)

Having discussed motivation and different modes of learning, it is important to discuss learning resources used during the learning processes. This discussion is particularly important to this research since knowledge of the existence, utility and usability of these different learning resources is closely associated with experience.

\section{Discussion}

To define knowledge in a "non-abstract and non-sweeping" is extremely difficult (Alvesson, 1993). If knowledge is dissociated from practice and experience, it easy becomes "everything and nothing" (Wikstrom and Normann, 1994). This was very clear in the responses provided by the interviews in this research. Learning and tacit knowledge acquisition are not abstract concepts and are closely related to their daily practice, problem solving and difficulties. In their pragmatic view, there is no learning without purpose and need. There is no theoretical knowledge management, but instead purposeful and intentional learning and sharing practices. Mostly unaware of academic theoretical and philosophical thinking as well as abstract conceptualizations of knowledge, their responses are pragmatically linked with their need for efficient work, aspirations for professional progression, peer recognition and at times self-rewarding learning. Bridging between the academic and practitioner worlds was one of the aims of this study as reflected in the first research question. As proposed by Nunes et al. (2005), more studies and publications in the KM field should focus on real case studies in order to close the gap between theoretical propositions and the reality of practice. This implies considering practitioners in knowledge 
intensive organizations as much more than "agents of formal knowledge" (Burris, 1993) but active creators of knowledge through articulation and externalization of their own tacit knowledge, which is necessary in order to support others both in their companies and in the sector as a whole.

Alvesson (1993) proposes that in knowledge-intensive organizations, practitioners although normally highly educated people who acquire qualifications after the termination of their formal education, also require a variety of skills that are in demand in their sector which are relatively esoteric and hard to attain for the common person, and are associated with high prestige and comparatively high financial rewards (Starbuck, 1992). This is clearly so in this case-study where all interviewees had at least one university degree, and the majority master's degree. However, the value of formal education has been often questioned by the practitioners interviewed. A several participants and one of the managers were particularly incisive about this issue claiming that although the "university has taught them some conceptual knowledge" (I35.9.23.D), that was "basic knowledge for getting started" (I38.10.41.T), sometimes even "too simple and totally not related with real practical applications" (I35.3.9.D). There were several other interviewees that commented on this issue:

\begin{abstract}
"Knowledge needs to be practised in the actual operation. Because learning from books, you might understand, but when you start to operationalize it, you will find that in fact you can't. This is the reality of software development." (I3.14.14.CM)

"Moreover, there is very little work-related learning in the university. After graduation, you will find you are not capable of work in the practice, because in the school or university, the knowledge you learn was just basics for a beginner. Certainly, there is more in-depth experience required in work." (I6.3.8.D)
\end{abstract}

These advanced technical skills as well as necessary social and research skills presuppose that a more complex and experience rooted knowledge acquisition process occurs during professional practice than the one that characterizes formal education that, with only a few exceptions, can only provide standardized knowledge (Alvesson, 1993). A key characteristic of the knowledge associated with these skills is the capacity to solve complex problems through creative and innovative solutions (Koskinen and Vanharanta, 2002). Moreover, the value and usefulness of these skills becomes dependent on technical changes, market mechanisms, accepted professional practices, changing ethical values and on societal changes. This was certainly the opinion that emerged from the interviews.

"For technical people, if you only know technology, then your career is finished. [...] Well, you certainly want to expand into other areas. If you want to develop, you definitely should have knowledge of other areas." (I20.5.23.D)

Data analysis showed that self-motivation for continuous professional development is clearly increased by experience acquired during the SW development processes by engagement with both technical and soft skills. Therefore, the awareness of personal development needs beyond technology was often a reflection from past experience and long-term development 
throughout individuals' careers. For instance, one of the interviewed project managers explained:

"That is right. [When the capability of technology has reached to a certain level], you could explore the other abilities [to grow]. There is no way to say that technology skills for an individual have reached their upper limit. But after these (the ability of using technology) have reached a certain level, for the personal development, there would have many aspects and directions to pursue." (I11.3.30.PM)

Furthermore, interviewees showed a very clear awareness of the continuous and persisting changing nature of the sector: "the IT industry is in a process of constant development. The replacement of old by new knowledge is relatively fast." (I30.12.3.D) In order to "catch up with the changing speed" (I30.12.3.D), the awareness of challenges posed by a fast changing technical environment was seen as a fundamental skill for SW practitioners and a key factor in their professional success. This point was also clearly explained by one of the developers and one of the managers:

"Because, like software, the software development technologies and methods update very fast ... Many new technologies continually appear. If you do not have a strong self-learning ability, then you will not be able to catch up." (I6.2.35.D)

"It requires some technical skills and needs continuous learning. Because the IT industry is changing so fast ... it changes almost every eight months or so. I should keep an attitude that I need to constantly learn and understand the new technologies." (I4.3.18.M)

This realization is the main motivational driver for these practitioners' engagement with continuous and unpredictable learning and development. The two modes that emerged were individual learning and peer supported learning (learning with/from others). The agreement of all interviewees with this point is to a certain point predictable and rather reasonable. What was more surprising was the apparent lesser value attributed to individual learning in relation to peer knowledge sharing, which was clearly the preferred and most commonly used process for rapid learning, just-in-time problem solving and rich discussion. The crucial nature of this peer knowledge sharing is a more interesting finding and, to a certain extent, unexpected in a sector that is highly competitive and, at times, secretive. The open and frank knowledge interchange both internally in their organizations and externally with the wide sector, including direct competitors was more surprising. It is perhaps the reaction of an entire professional community to the inexorable changing pace to which it is subject, and the realization that, without a communal collegial effort, mutual survival would be at risk. Specific sector somatic knowledge and sector specific cultural perceptions seem therefore to be fundamental in understanding the need for tacit knowledge acquisition.

\subsection{A Habitus-driven Individual Development Theoretical Model}

If individual development is deemed the fundamental feature for professional success and survival in the continuously changing environment of the SW industry, it is then important to determine the drivers for such a clear awareness by the SW development practitioners. 
Alvesson (1993) proposes that, in order to acquire useful work specific skills, professionals make use of somatic and cultural knowledge as well as externalized tacit knowledge acquired through experience. Awareness and motivation to engage in continuous individual development depends on cultural knowledge, somatic knowledge and of course habitus of engaging in learning activities.

Knowledge built into organizational and sector culture and consequently into people's ways of thinking and doing things (Karreman and Alvesson, 2004). Therefore, culture knowledge becomes a form of tacit knowledge that becomes part of experienced practitioners behaviours, attitudes and perceptions. Culture knowledge represents a prerequisite for the ability to master a particular symbolic and value environment; to decipher the cultural codes; manoeuvre freely in a social setting; and is necessary for social successful professional behaviour (Alvesson, 1993; Bourdieu, 1979; Swidler, 1986). Engaging in continuous individual learning and professional development seems to have become part of the culture knowledge in the SW sector.

"To do this technical job, you definitely need to keep learning new things. Because IT is changing so fast .... In order to cope with your work, you need to continuously gain new knowledge." (I18.5.22.PM)

"Coding is actually a very hard work. If you want work it well, you have to work harder. Like I said before, the best way to work on coding is to keep learning." (I25.19.19.M)

This collective awareness for the need for continuous life-long learning (refs) in the SW sector creates a strong sense of learning and sharing in individual practitioners. Contrary to other professional environments and sector cultures, knowledge sharing became an integral element of professionals' somatic knowledge and companies' cultures.

"We share with each other very often. Here, we have a group chatting message board which is the RTX tool that resides in our company's internet. [interviewer requested explanation] ... You can understand it as a $Q Q$ chatting group, an instant message tool. It was designed by our own company [Yirong] and is used for internal sharing within teams." (I9.4.3.D)

"We do have a sharing knowledge facility in the $Q Q$ groups. Sometimes I share with friends, sometimes I share with colleagues from our company. That is, if they ask some questions [in QQ group chatting], someone would answer or sometimes I would respond myself to the questions." (I23.18.23.PM)

Somatic knowledge related to sharing and learning from more experienced others is clearly evident from the quotations above. The two different organizations mentioned provide the sharing and communication facilities, but the individuals are active consumers and producers of knowledge and information and depend of these facilities to learn. Somatic knowledge, first discussed in the context of knowledge management by Alvesson (1993), is predicated on theoretical principles of somatic science as proposed by Hanna (1970). Individuals are seen as living organisms (somas), which are an integral and ordered processes of both physical and 
knowledge embodied elements which cannot be separated either from their evolved past or their adaptive future. A professional practitioner, as a soma, is an embodiment of processes that endure and adapt through time. Therefore, individuals develop and construct knowledge through action and experience in particular environments, at particular times and habituated by the culture in which they live in. Culture knowledge and somatic knowledge reinforce each other and develop habitus.

Habitus (not to be confused with habit) is a theoretical structure that was first proposed by Bourdieu (1968) and well defined by Lizardo (2004) as a generative dynamic structure that adapts and accommodates itself to other dynamic meso-level structures composed primarily of other actors, situated practices and durable institutions. As such, the individual practitioner is a social agent subject to developmental, cognitive and emotive constraints and affected by the very real physical, cultural and institutional configurations that compose their professional practice. Therefore, habitus is a theory of individual action that is constrained by the systemic structuration of the agency (King, 2000; Lizardo, 2004). The practices produced by the habitus are strategy-generating principles enabling individual practitioners to cope with unforeseen and ever-changing situations (Bourdieu, 1977). In this sense, it was clear from the statements of the participants in this research project, that the awareness of the ever-changing nature of the SW industry associated with the need to stay current with emerging technologies, methods and practices created a strong knowledge sharing and individual learning habitus in professionals in the sector.

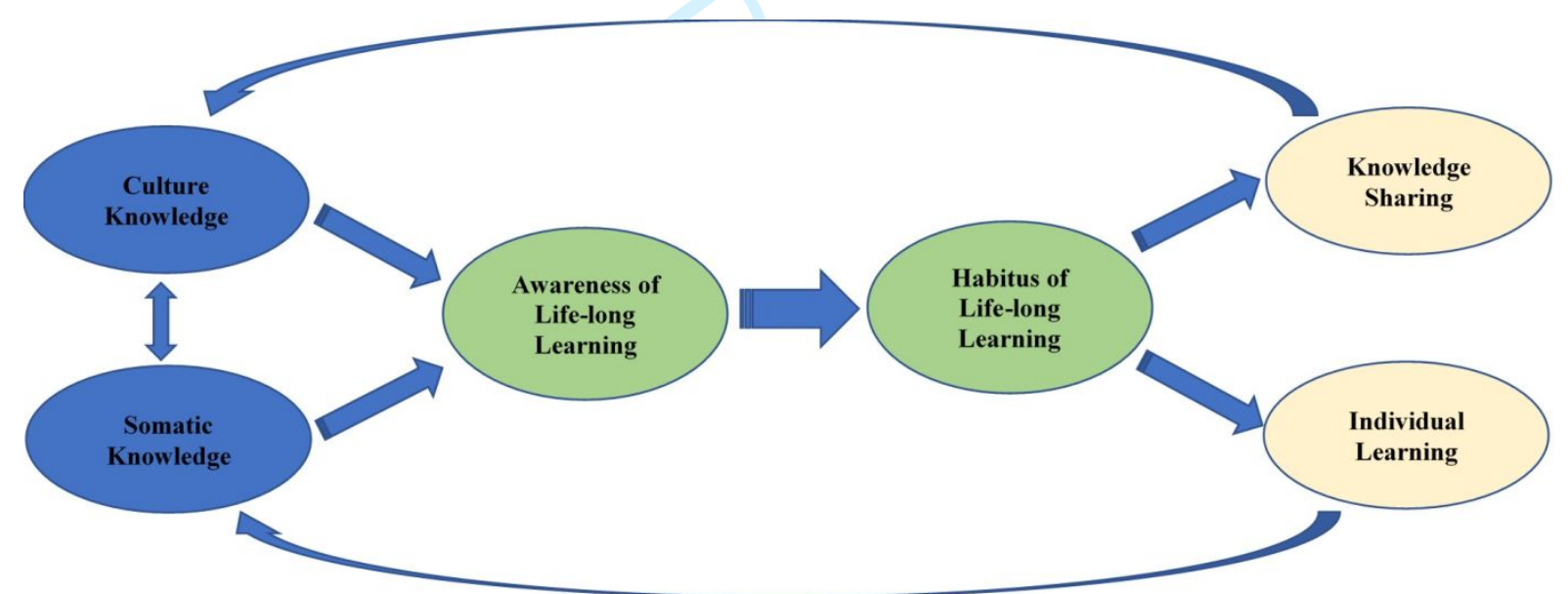

Figure 5. A Habitus-Driven Individual Development (HDID) Theoretical Model

This discussion resulted from the inductive GT practice of integrating and placing the findings of the research in the existing body of knowledge, led to the integrative theoretical model presented in Figure 5. Sector and organizational culture knowledge in the SW sector moulds, and is strongly influenced by, somatic knowledge of individual practitioners. These types of knowledge lead to the creation of strong awareness for the need for lifelong learning practices. This awareness results in habitus of both knowledge sharing and individual learning. Well-accepted and wide spread knowledge sharing practices in the sector reinforce culture knowledge in the sector. Individual learning and its application in practice reinforces somatic knowledge concerned with awareness for the need of life-long learning. The HDID model reinforces the notions proposed by Bourdieu (1990) that habitus are structures that result in structuring actions - knowledge sharing and individual learning - that in turn contribute to the reinforcement of the structuring process - culture knowledge and somatic knowledge - making the habitus permanent. 
This model may also explain why in other industrial and business contexts there is not such a strong culture of knowledge sharing and individual development. If the conditions for the creation of individual somatic knowledge are not present and the pressures of constant change do not create a culture of awareness of the importance of sharing and learning, then habitus will not emerge and both knowledge sharing and continuous individual development may not become a permanent feature.

\subsection{A Pragmatic SW Industry Knowledge Taxonomy}

However, in the context of the three case-studies, the very concept of tacit knowledge has proven to be rather abstract and not well understood by the SW development community. Project managers, designers, programmers, testers, installation experts do not think in terms of the traditional KM dichotomy of explicit and tacit knowledge. In fact, these two terms (or recognizable synonyms) were never found $(0$ occurences $)$ in the total of 44 interviews transcripts analyzed. Conversely, it was clear from the analysis that practitioners in the SW industry were referring to three types of knowledge that, in their understanding, enabled and constrained their SW development agency:

- Implicit Knowledge - The continuously generated knowledge that is built through social negotiation within the sector and represents the collective understanding of how work is done, the main technologies and methods used in that sector.

- Procedural Knowledge - The knowledge that is specific to each organization within the sector and is related on how things are done in that particular environment and in that specific organizational culture.

- Experience - The individual tacit knowledge acquired by the practitioners through their agency in the organization and interaction with peers, managers and customers.

Therefore, the Industry Knowledge Taxonomy presented in Table 1 synthesizes the basic epistemological position of this study and provides a clear indication how the researchers interpreted the concept of tacit knowledge in this context of practice. According to the data analysis most of the knowledge shared by practitioners across the sector is either implicit or individual knowledge. Procedural knowledge is mostly used internally in the organization and there is clear evidence that this type of knowledge is well and efficiently shared in organizations. From an individual perspective all these three types of knowledge are clearly valued by the practitioners and acquired either by individual learning strategies or by interactions with their peers. Thus, this taxonomy also adds detail and explanation the HDID model presented in Figure 5.

In order to bridge between KM theory and the reality of practice in the SW industry, the researchers had to map these three main types of professional knowledge against the traditional dichotomous epistemological propositions first proposed by Nonaka and Takeuchi's (1994). This effort enabled the required focus on tacit knowledge that was necessary to respond to the study's research questions and resulted in the SW Industry Knowledge Taxonomy proposed in Table 1. 


\begin{tabular}{|c|c|c|c|c|}
\hline \multirow[b]{2}{*}{$\begin{array}{c}\text { Types of } \\
\text { knowledge }\end{array}$} & \multicolumn{2}{|c|}{$\begin{array}{c}\text { Traditional Representation } \\
\text { of Knowledge }\end{array}$} & \multirow[b]{2}{*}{ Origin } & \multirow[b]{2}{*}{ Epistemological Scope } \\
\hline & $\begin{array}{c}\text { Tacit } \\
\text { Knowledge }\end{array}$ & $\begin{array}{c}\text { Explicit } \\
\text { Knowledge }\end{array}$ & & \\
\hline $\begin{array}{c}\text { Implicit } \\
\text { Knowledge }\end{array}$ & & $=$ & Sector & $\begin{array}{l}\text { What is the knowledge } \\
\text { that is necessary to } \\
\text { work in a sector? } \\
\text { (e.g. quality standards, } \\
\text { methodologies, } \\
\text { methods, tools, etc ) }\end{array}$ \\
\hline $\begin{array}{l}\text { Procedural } \\
\text { Knowledge }\end{array}$ & $\sqrt{ }$ & $\sqrt{ }$ & Organization & $\begin{array}{l}\text { What is the knowledge } \\
\text { that is necessary to } \\
\text { work in an } \\
\text { organization? } \\
\text { (e.g. process handbook, } \\
\text { organizational norms, } \\
\text { organizational culture, } \\
\text { etc) }\end{array}$ \\
\hline Experience & $\sqrt{ }$ & & Individual & $\begin{array}{l}\text { What is the knowledge } \\
\text { that individuals recall } \\
\text { and use to work? }\end{array}$ \\
\hline
\end{tabular}

Table 1. SW Industry Knowledge Taxonomy

This Industry Knowledge Taxonomy is an unintended contribution of this study as it was neither an explicit objective nor the object of a specific research question. The fact that this emerged as a research output confirmed that the inductive approach adopted by using GT seems to have been very successful. The emergent theory seems to be indeed grounded in the context of case-studies rather than biased by the prevalent literature review. In this sense, the findings of this research are very different from those that would have emerged from a deductive approach (for instance a questionnaire based survey) that would either prove or disprove a priori defined theories deduced for the existing literature on the field.

The theories (the HDID model and Industry Knowledge Taxonomy) proposed in this paper are strongly grounded and discussed in the Chinese context. However, it is reasonable to expect that, despite obvious cultural differences, this industry's processes, procedures and standards create strong similarities in the way professionals act and acquire experience worldwide. Therefore, it is hoped that the findings and theoretical propositions in this study may be transferable and used to explain experience in other national contexts elsewhere. Therefore, future work should aim at testing transferability and generalisation of the propositions of this paper to the wider SW industry.

\section{Conclusions}

This study was contextualized and grounded in the agency of practitioners in the SW industry in China. It clearly showed that this is a particularly interesting and unique context due to the unstoppable, relentless and increasingly fast change that characterizes the sector. The findings reveal that SW development practitioners are well aware of the need for life-long learning and continuous individual development. These processes were divided by the initial coding process into two main categories: individual learning and learning from others. The study confirmed that knowledge sharing is a prevalent practice in the sector and within the organizations. This led to a clear theoretical understanding that the continuous change that faces the sector has led to individual acquisition of culture and somatic knowledge that, in 
turn, lay the foundation for not only the awareness of the need for continuous individual professional development, but also for the creation of habitus related to knowledge sharing and continuous learning. This makes the SW sector different from other competitive sectors where secrecy and insulation of knowledge are characteristics. This is synthesized and described in the Habitus-driven Individual Development Theoretical Model presented in the paper. Additionally, an analysis of the types of knowledge shared and acquired led to the SW Industry Knowledge Taxonomy presented in Table 1.

The findings and the emergent theoretical conceptualizations presented in the discussion, clearly show how inductive qualitative studies do not need to reinvent the wheel. In fact, even in the more purist of inductive approaches, such as Grounded Theory, the researcher is required to try to relate the findings to existent theoretical propositions. This often leads to deeper theoretical insights and contextualization of the emergent theories resulting from the inductive process. In the case of this research, it resulted in the two conceptualizations presented in Figure 5 and Table 1. These conceptualizations are richer than just the direct answers to the research questions and clearly contribute more to the current body of knowledge in KM.

Finally, although significant contributions have been proposed, the research findings and theoretical conceptualizations presented above should, be seen as a first step in the understanding of this problem area. Future work should consider testing of the theoretical model in other sectors and further inductive research into a more rich variety of possible contexts, which could provide further insights or contrasts as determined by good theoretical sampling practices.

\section{Acknowledgements}

The work was supported by the China Postdoctoral Science Foundation (grant number: 2017M620997) and by a "100 Talent" Seed Research Fund of the Sun Yat-sen University (grant number: 2000-18831100), Guangzhou, China.

\section{References}

Alavi, M. \& Leidner, D. 2001, "Review: knowledge management and knowledge management systems: conceptual foundations and research issues", MIS Quarterly, vol. 25, no. 1, pp. 107-136.

Alvesson, M. 1993, "Organization as rhetoric: knowledge-intensive companies and the struggle with ambiguity", Journal of Management Studies, vol. 30, no. 6, pp. 997-1015.

Alvesson, M. 1995, Management of Knowledge-Intensive Companies, de Gruyter, Berlin.

Amalia, M. \& Nugroho, Y. 2011, "An innovation perspective of knowledge management in a multinational subsidiary", Journal of Knowledge Management, vol. 15, no. 1, pp. 71-87.

Argyris, C. \& Schon, D. 1978, Organizational Learning, Addison-Wesley, Reading MA.

Beckman, T. 1997, "A methodology for knowledge management", Proceedings of International Association of Science and Technology for Development AI and Soft Computing Conference:Banff, Alberta, Canada, 1997. 
Botha, A., Kourie, D. \& Snyman, R. 2008, Coping with continuous change in the business environment: Knowledge management and knowledge management technology, Chandos Publishing Limited, Oxford.

Bourdieu, P. 1968, "The international scene: current trends in the social sciences: structuralism and theory of sociological knowledge", Social Research: An International Quarterly, vol. 35, no. 4, pp. 681-706.

Bourdieu, P. 1977, Outline of a Theory of Practice, Cambridge University Press, Cambridge.

Bourdieu, P. 1979, Distinction: A Social Critique of the Judgement of Taste, Routledge, London, UK.

Brown, S.L. \& Eisenhardt, K.M. 1997, "The art of continuous change: linking complexity theory and time-paced evolution in relentlessly shifting organizations", Administrative Science Quarterly, vol. 42, no. 1, pp. 1-34.

Brown, S.L. \& Eisenhardt, K.M. 1998, Competing on the Edge: Strategy As Structured Chaos, Harvard Business School Press, Boston, Mass.

Burris, B. 1993, Technocratic Organization and Ideology, State University of New York Press, Albany.

Carayannis, E.G. 1999, "Fostering synergies between information technology and managerial and organizational cognition: the role of knowledge management", Technovation, vol. 19, pp. 219-231.

Cavusgil, S.T., Calantone, R.J. \& Zhao, Y. 2003, "Tacit knowledge transfer and firm innovation capability", Journal of Business \& Industrial Marketing, vol. 18, no. 1, pp. 621.

Chen, H. 2015, Identification and Classification of Shareable Tacit Knowledge Associated with Experience in the Chinese Software Industry Sector, Degree of Doctor of Philosophy ed, Loughborough University, UK.

Chen, H., Nunes, J.M., An, X. \& Bai, W. 2016, "Motivation and awareness for tacit knowledge sharing in Chinese software organizations", Proceedings of the 13th International Conference on Intellectual Capital, Knowledge Management \& Organisational Learning (ICICKM 2016)Ithaca College, New York, USA, 14-15 October 2016, pp. 73-81.

Chen, H., Ragsdell, G., O'Brien, A. \& Nunes, M.B. 2012, "A proposed model of knowledge management in the software industry sector", Proceedings of 7 th International Conference on Digital Information Management(ICDIM)University of Macau, Macau, 22-24 August, pp. 291-296.

Cockburn, A. \& Highsmith, J. 2001, "Agile software development: the people factor", IEEE Computer, vol. 34, no. 11, pp. 131-133. 
Cook, S. \& Brown, J. 1999, "Bridging epistemologies: the generative dance between organizational knowledge and organizational knowing", Organization Science, vol. 10, no. 4 , pp. 381-400.

D'Aveni, R.A. 1994, Hypercompetition: Managing the Dynamics of Strategic Maneuvering, Free Press, New York.

Dewey, J. 1922, Human Nature and Conduct. An Introduction To Social Psychology, Allen and Unwin, London.

Dingsoyr, T. 2002, "Knowledge management in medium-sized software consulting companies", Empirical Software Engineering, vol. 7, no. 4, pp. 383-386.

Eisenhardt, K. 1989, "Building theories from case study research", The Academy of Management Review, vol. 14, no. 4, pp. 532-550.

Gao, F., Li, M. \& Clarke, S. 2008, "Knowledge, management and knowledge management in business operations", Journal of Knowledge Management, vol. 12, no. 2, pp. 3-17.

Glaser, B.G. \& Strauss, A.L., 1967. The discovery of grounded theory: strategies for qualitative research, 1st ed. A Division of Transaction Publishers, New Brunswick and London.

Hanna, T. 1970, Bodies in Revolt: A Primer in Somatic Thinking, Holt, Rinehart and Winston, Austin.

Highsmith, J. \& Cockburn, A. 2001, " Agile software development the business of innovation", Computer, vol. 34, no. 9, pp. 120-127.

Israel, S. Mar 18, 2013, Marc Benioff to write age of context foreword [Homepage of Forbes], [Online]. Available: https://www.forbes.com/sites/shelisrael/2013/03/18/marc-benioffto-write-age-of-context-foreword/\#316ed0f94a10 [Octorber 16, 2017, .

Jashapara, A. 2011, Knowledge Management: An Integrated Approach, 2nd edn, Prentice Hall, Englewood.

Karreman, D. \& Alvesson, M. 2004, "Cages in tandem: management control, social Identity, and identification in a Knowledge-intensive firm", Organization, vol. 11, no. 1, pp. 149175.

King, A. 2000, "Thinking with Bourdieu Against Bourdieu: A 'Practical' Critique of the Habitus", Sociological Theory, vol. 18, no. 3, pp. 417-433.

Koskinen, K.U. \& Vanharanta, H. 2002, "The role of tacit knowledge in innovation processes of small technology companies", International Journal of Production Economics, vol. 80, pp. 57-64.

Lizardo, O. 2004, "The cognitive origins of Bourdieu's habitus", Journal for the Theory of Social Behaviour, vol. 34, no. 4, pp. 375-401. 
Marwick, A.D. 2001, "Knowledge management technology", IBM Systems Journal, vol. 40, no. 4 , pp. $814-830$.

McEvily, S., Das, S. \& McCabe, K. 2000, "Avoiding competence substitution through knowledge sharing", The Academy of Management Review, vol. 25, no. 2, pp. 296-311.

Mishra, B. \& Bhaskar, A.U. 2011, "Knowledge management process in two learning organisations", Journal of Knowledge Management, vol. 15, no. 2, pp. 344-359.

Narayandas, D. \& Kasturi, R. 1995 October, Dell Computer Corporation, Harvard Business School Case 596-058, US.

Nonaka, I. 1994, "A dynamic theory of organizational knowledge creation", Organization Science, vol. 5, no. 1, pp. 14-37.

Nonaka, I., Toyama, R. \& Konno, N. 2000, "SECI, Ba and leadership: a unified model of dynamic knowledge creation ", Long Range Planning, vol. 33, no. 1, pp. 5-34.

Nunes, M.B., Annansingh, F., Eaglestone, B. \& Wakefield, R. 2005, December, "Managers' perceptions of the value of knowledge management in small and medium sized knowledge-intensive enterprises (SMEs)", Journal of Knowledge Management Practice, [Online], . Available from: http://www.tlainc.com/articl104.htm. [15 Octorber 2017].

Nunes, M.B., Annansingh, F., Eaglestone, B. \& Wakefield, R. 2006, "Knowledge management issues in knowledge-intensive SMEs ", Journal of Documentation, vol. 62, no. 1, pp. 101-119.

Price, L. 1954, Dialogues of Alfred North Whitehead, Little, Brown, Boston, MA.

Rodon, J. \& Pastor, J. 2007, "Applying grounded theory to study the implementation of an inter-organizational information system", The Electronic Journal of Business Research Methods, vol. 5, no. 2, pp. 71-82.

Sofware AG. 2005, Innovate Differentiate and Win in the Digital World, Software AG Annual Report, Darmstadt, Germany.

Starbuck, W. 1992, "Learning by knowledge-intensive firms", Journal of Management Studies, vol. 29, no. 6, pp. 713-740.

Strauss, A. \& Corbin, J. 1998, Basics of qualitative research: techniques and procedures for developing Grounded Theory, 2nd ed edn, Sage, Thousand Oaks, CA.

Swidler, A. 1986, "Culture in action: symbols and strategies", American Sociological Review, vol. 51, no. 2, pp. 273-286.

Venkitachalam, K. \& Busch, P. 2012, "Tacit knowledge: review and possible research directions", Journal of Knowledge Management, vol. 16, no. 2, pp. 357-372.

Vickers, G. 1976, Technology and culture, Division for Study and Research in Education, Massachusetts Institute of Technology, Cambridge, MA. 
Wikstrom, S. \& Normann, R. 1994, Knowledge and value: a new perspective on corporate transformation, Routledge, London.

Wilson, T.D. October 2002, "The nonsense of 'knowledge management"', Information Research, [Online], vol. 8, no. 1. Available from: http://informationr.net/ir/81/paper144.html. [10 July 2017]. 


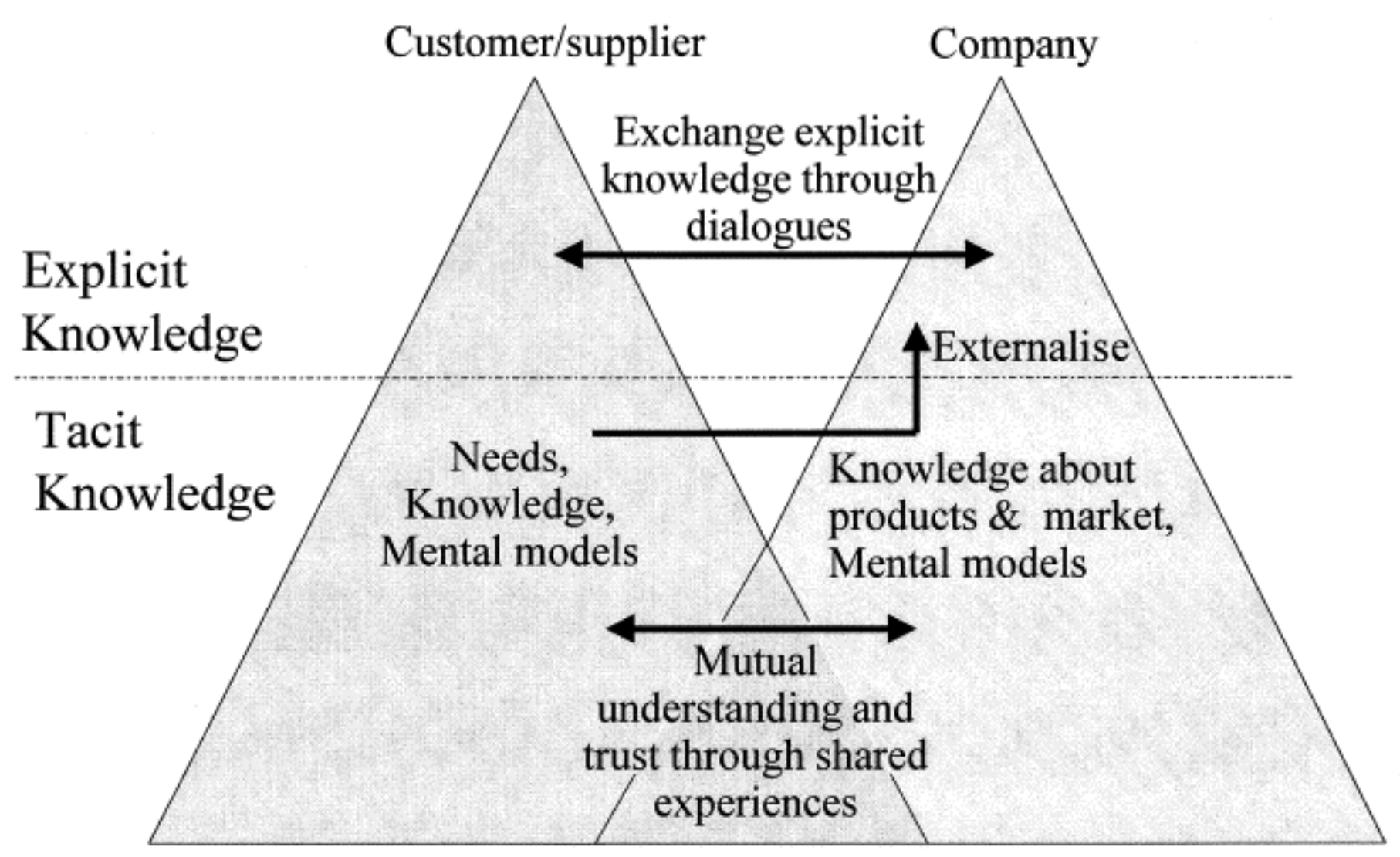

Figure 1 Knowledge creation in organizational environments (Nonaktal., 2000) 
b) Capturing Requirements Phase 客户需求调研。

What kind of experience and knowledge do you think could help you to specify and express customers' needs, and definite in terms of system's interface?

您认为什么样经验和知识能够帮助您捕捉和表述客户的需求, 并转化为专业技术语言记录下 来? 。

What kind of knowledge do you think it could help you to understand and analysis the customers' requirements?

您认为什么样经验和知识能够帮助您理解和分析客户的需求?

What kind of knowledge do you think it could help you to present the customers' needs in term of both business and technical level?

您认为什么样经验和知识能够帮助您从业务和技术应用的层面表达出客户的需要?

When you work with others, do you think there are any skills inxolved which can challenge or affect the efficiency of your working? (good communication channels, efficient work division and good leadership).

当您与他人共事时, 您认为什么样的技能可能会影响或帮助您的工作效能? (好的沟通渠道, 有效的工作分工，好的领导才能）

What type of knowledge from the projects you are on now would you like to transfer to new projects?

您现在这个项目中所运用的什么样知识, 会积累运用下一个项目中?

What type of knowledge has been suitable for reuse from the projects you have been working on earlier?

您现在这个项目中运用的那些知识, 是来自于上一个项目的积累？
Figure 2Illustration of the semi-structured interview script used in this research 


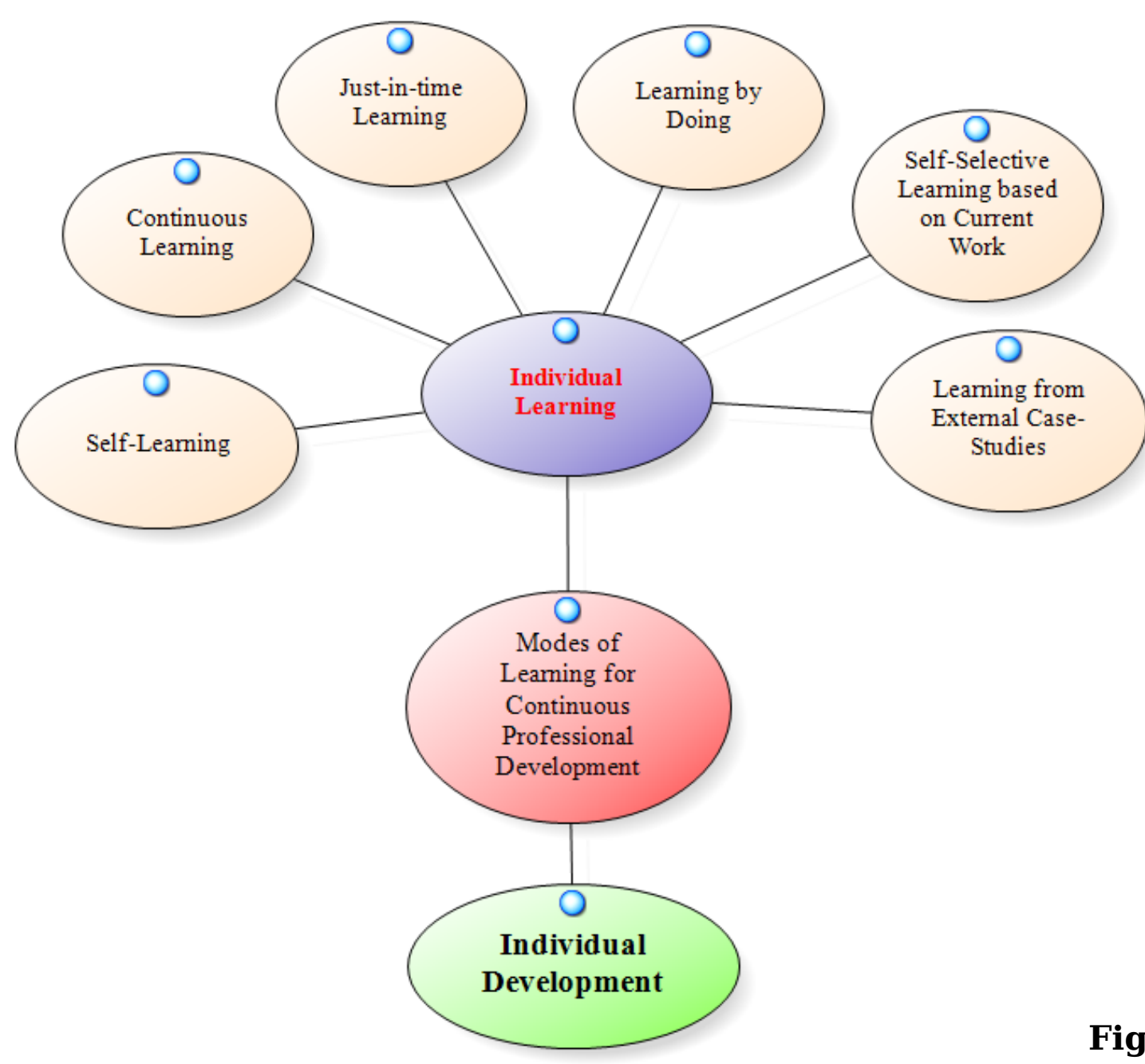

Figure 3Individual Learning Modes in the SW Sector 
Figure 4Peer Supported Learning Modes in the Sector 


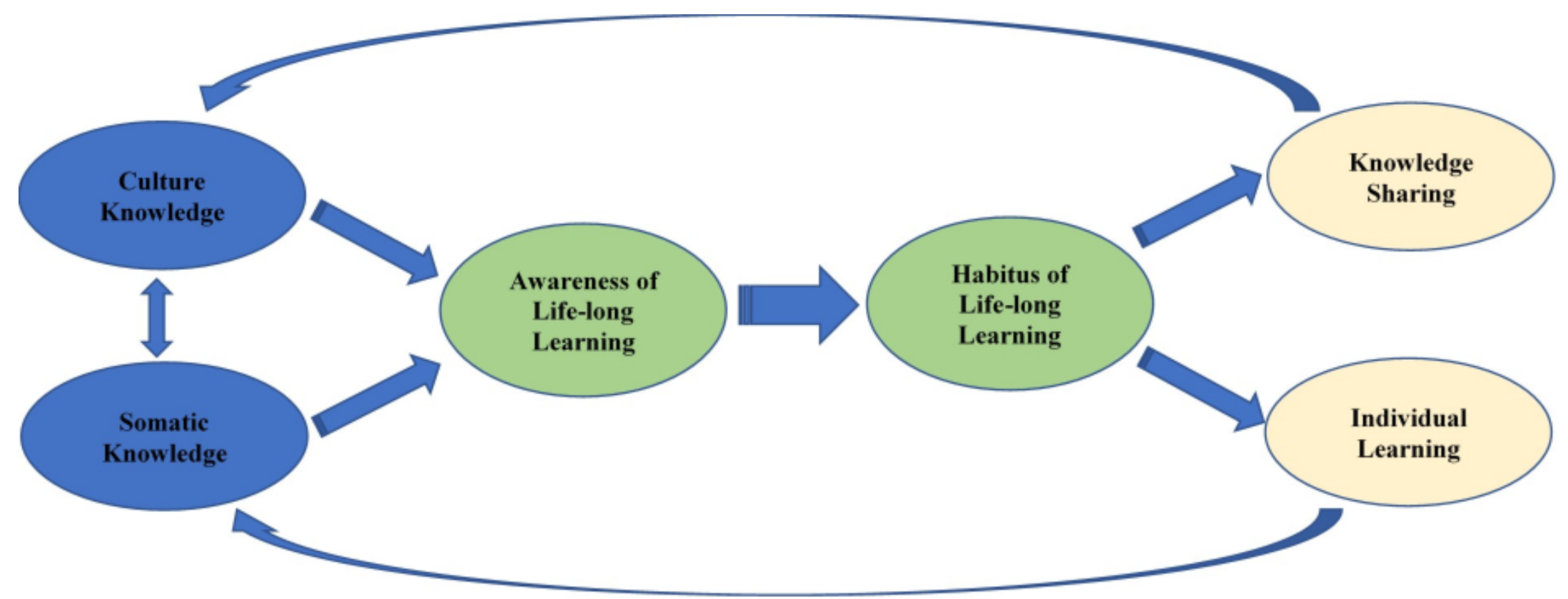

Figure 5A Habitus-Driven Individual Development (HDID) Theoretical Model 


\section{Review Comment (AB)}

Expand the method section to include more detail to explain exactly how the interviews enabled participants to discuss issues of tacit knowledge; whether you include an interview schedule or simply describe the process is for you to decide.

Explain fully the types of individual learning distinguished, and answer the reviewers comment that "the variously separated types of individual learning seem to be less distinct than presented e.g., continuous learning could be applied to several of the other categories in this section (a person might continuously learn by doing (merging two categories here) or learning 'just in time' might be another form of learning based on 'current work needs')".

Provide justification for your results, in light of the reviewer's comment that "there is no distinction made between companies or weightings given to the relative proportion of each instance, leaving the reader with little concrete data on which to draw conclusions".

Give further discussion of the " taxonomy that adds a category of procedural knowledge to the traditional tacit-explicit dichotomy", in light of the reviewer's comment that "I am not clear what this is supposed to provide the reader ... It seems this is based on the data in the cases but by just briefly introducing it at the end, I am not clear what purpose it serves"

\section{Correction/Response}

Explanation added in section 3.3 Data Collection and Analysis and coded in blue. The red text was added in the previous review correction.

Explanation added in section 4.1 Individual Learning and coded in blue. The text was added before the last paragraph in this section.

Explanation added that the use of the three companies is due to section 3.2 theoretical sampling in section 3.2 Research Design and Approach, 2nd to 5 th paragraphs, marked in blue.

This section was almost entirely re-written. Extensive explanations section 5.2

Section/Page

section 3.3

section 4.

were made and marked in blue. These were made all throughout this section and not confined to isolated paragraphs. 